\title{
Simultaneous removal of phosphorus and nitrogen from sewage using a novel combo system of fluidized bed reactor-membrane bioreactor (FBR-MBR)
}

Awoke Guadie ${ }^{\mathrm{a}}$, Siqing Xia ${ }^{\mathrm{b}, *}$, Zhiqiang Zhang ${ }^{\mathrm{b}}$, Wenshan Guo ${ }^{\mathrm{c}}$, Huu Hao Ngo ${ }^{\mathrm{c}}$, Slawomir W. Hermanowicz ${ }^{\mathrm{d}, \mathrm{e}}$

a'UNEP-Tongji Institute of Environment for Sustainable Development, College of Environmental Science and Engineering, Tongji University, Shanghai 200092, China

${ }^{\mathrm{b}}$ State Key Laboratory of Pollution Control and Resource Reuse, College of Environmental Science and Engineering, Tongji University, Shanghai 200092, China

${ }^{\mathrm{c} C e n t e r}$ for Technology in Water and Wastewater, School of Civil and Environmental Engineering, University of Technology Sydney, Sydney, NSW 2007, Australia

${ }^{\mathrm{d}}$ Department of Civil and Environmental Engineering, University of California, Berkeley, California 94720, United States

${ }^{\mathrm{e}}$ National High-End Foreign Experts of China Program, Tongji University, Shanghai 200092, PR China

\section{Abstract}

A FBR-MBR combo system was designed as a novel approach for simultaneous phosphorus and nitrogen removal from sewage. The combo system was evaluated more than seven months under variable $\mathrm{pH}$ (7.5-9.5), hydraulic retention times (HRT=2-10 h), intermittent aeration cycles (IAC) (on/off=60/60-15/45 min) and sludge retention times (SRT=10-60 d). Prior recovery of phosphorus as struvite in the FBR enhanced nitrogen and COD removal efficiency in MBR. Under optimum operating conditions ( $\mathrm{pH}=9, \mathrm{HRT}=6 \mathrm{~h}$ and $\mathrm{IAC}=45 / 15 \mathrm{~min}$ ), $\mathrm{PO}_{4}{ }^{3-}-\mathrm{P}, \mathrm{NH}_{4}{ }^{+}-\mathrm{N}$ and COD removal efficiencies were $92.6 \pm 4.2,98.7 \pm 1.2$ and $99.3 \pm 0.5 \%$, respectively. Stable mixed liquor suspended solid concentration (3.0-5.0 g/L); enhanced nitrification-denitrification activity (78-92\%) and reduced transmembrane pressure were also achieved. Compared to soluble microbial products, extracellular polymeric substances (EPS) showed strong correlation with fast membrane fouling. Among EPS components, carbohydrate rather than protein was associated with membrane fouling. Except HRT, all parameters considered (pH, IAC, SRT) showed a significant effect on removal efficiency.

Keywords: Fluidized bed reactor; Membrane bioreactor; Nitrogen; Phosphorus; Sewage

${ }^{*}$ Corresponding author. P.O. Box 200092, Shanghai, China. E-mail: siqingxia@gmail.com Tel.: +86 21 65980440; fax: +86 2165986313. 


\section{Introduction}

Wastewater discharge standards have become more strictly controlled due to severe eutrophication and environment pollution (Holakoo et al., 2007; Guo et al., 2009). As a result, wastewater treatment techniques are currently becoming more and more sophisticated that shift from sole chemical oxygen demand (COD) removal to simultaneous COD, nitrogen and phosphorus removal (Qiu et al., 2010). During the last decade, the technical and scientific community showed a growing interest in developing innovative technologies that remove these pollutants from wastewater (Adnan et al., 2003; Guo et al., 2009; Kornboonraksa et al., 2009; Ng et al., 2011).

In recent years, fluidized bed reactor (FBR) has gained significant attention for phosphorus removal and recovery (Le Corre et al., 2007; Pastor et al., 2008; Guadie et al., 2013). It is well understood that under alkaline condition, phosphorus reacts with nitrogen and magnesium to produce struvite (Eq. 1). Struvite $\left(\mathrm{MgNH}_{4} \mathrm{PO}_{4}\right)$ formation occurs either spontaneously or intentionally when the $\mathrm{Mg}: \mathrm{NH}_{4}: \mathrm{PO}_{4}$ molar ratio $\geq 1: 1: 1$ (de-Bashan and Basha, 2004). Spontaneous struvite formation most likely occurs in pipeline locations (such as junctions, elbows, etc.) where carbon dioxide stripping and causing $\mathrm{pH}$ raise. In contrast, intentional struvite formation using reactors is now getting more attention as it has numerous advantages, including serving as slow released fertilizer, reducing sludge volume, removing phosphorus and nitrogen simultaneously, replacing natural phosphate used in industries, and avoiding pipe clogging/treatment failures (Munch and Barr, 2001; de-Bashan and Basha, 2004; Pastor et al., 2008).

$$
\mathrm{Mg}^{2+}+\mathrm{NH}_{4}^{+}+\mathrm{H}_{n} \mathrm{PO}_{4}^{n-3}+6 \mathrm{H}_{2} \mathrm{O} \rightarrow \mathrm{MgNH}_{4} \mathrm{PO}_{4} * 6 \mathrm{H}_{2} \mathrm{O}+n \mathrm{H}^{+}, \quad n=0,1 \text { and } 2
$$


Although struvite recovery using FBR requires an equal molar ratio of phosphorus and nitrogen, the higher concentration of nitrogen that wastewater normally contain leads inadequate removal of nitrogen. Thus, another treatment approach that involves the subsequent removal of nitrogen from wastewater is needed. Currently, membrane bioreactor (MBR) is widely used as an attractive option for treatment of nitrogen and organic substances (Meng et al., 2007; Xia et al., 2008; Ng et al., 2011). Compared to conventional activated sludge processes, MBR treatment provides high removal efficiency, good effluent qualities, very long sludge retention time (SRT), short hydraulic retention time (HRT), stable mixed liquor suspended solids (MLSS) and enhanced nitrification (Fu et al., 2009). Despite these important advantages, the application of MBR has significant drawbacks such as membrane fouling, the amount of energy needed and subsequent membrane cleaning costs (Kornboonraksa et al., 2009). Particularly, membrane fouling (decline permeate flux) is the major hindrance that increases operational and maintenance cost (Meng et al., 2007).

Currently, unified and well-described mechanisms that can help to control membrane fouling has not been yet established (Xia et al., 2008). This is partly due to the adverse range of factors including biomass characteristics, operational conditions and membrane properties (Ahmed et al., 2007). Biomass characteristics such as MLSS concentrations, extracellular polymeric substances (EPS) and soluble microbial products (SMP) have been identified as a typical membrane fouling factors (Cho et al., 2005; Meng et al., 2007). Previous studies showed that EPS and SMP are composed of polysaccharides, proteins, lipids, and nucleic acids which might be the cause of membrane fouling (Xia et al., 2008). According to the report by Kornboonraksa et al. (2009), the carbohydrate detected from EPS is suggested to be the cause of membrane fouling. Trussell et al. 
(2006) also found good correlation between the SMP carbohydrate concentration and membrane fouling rate. Operational conditions such as HRT, SRT, and intermittent aeration cycle (IAC) on membrane fouling have also been documented in several reports. Since the change in HRT alters the organic load rate, it has a significant impact on MLSS. Higher organic load at shorter HRT increases the biomass in the activated sludge system which can lead to MBR fouling (Trussell et al., 2006). In addition to HRT, SRT has also a significant influence on MBR performance through changing the characteristic of MLSS as well as the physiological state of microbes. The formation of protein and carbohydrate was found to be higher at shorter SRT (Ahmed et al., 2007).

Although efficient treatment of phosphorus using FBR and removal of nitrogen using MBR has been documented in literature, to the best of our knowledge, only a few studies have previously been published about MBR combined with other systems for simultaneous removal of wastewater pollutants (Guo et al., 2009; Kornboonraksa et al., 2009; Yang et al., 2009; Ng et al., 2011; Phattaranawik and Leiknes, 2011; Nguyen et al., 2013). Therefore, the main goal of this research was to provide a fundamental understanding about the FBR-MBR combo system performance (i.e. removal efficiency and membrane fouling rate) at a range of operational conditions (HRT, SRT, pH, IAC) and biomass characteristics (ESP, SMP, MLSS).

\section{Methods}

\subsection{Wastewater characteristics}

The synthetic wastewater used in this study was prepared according to Xia et al. (2010) with some modifications. It contains starch (175 mg/L), glucose (200 mg/L), peptone (28 mg/L), urea (64 mg/L), ammonium chloride (150 mg/L), potassium dihydrogen phosphate (52.5 mg/L), 
magnesium chloride hexahydrate $(150 \mathrm{mg} / \mathrm{L})$, calcium sulfate dihydrate $(50 \mathrm{mg} / \mathrm{L})$ and trace element solution. Trace mineral solution containing (mg/L): $\mathrm{MnCl}_{2} \cdot 4 \mathrm{H}_{2} \mathrm{O}(30), \mathrm{H}_{3} \mathrm{BO}_{3}(300)$, $\mathrm{CoCl}_{2} \cdot 6 \mathrm{H}_{2} \mathrm{O}(10), \mathrm{CuCl}_{2} \cdot 2 \mathrm{H}_{2} \mathrm{O}(10), \mathrm{NiCl}_{2} \cdot 6 \mathrm{H}_{2} \mathrm{O}(10), \mathrm{ZnCl}_{2}(100)$ and $\mathrm{FeSO}_{4} \cdot 7 \mathrm{H}_{2} \mathrm{O}$ (300) was prepared separately and stored at $4^{\circ} \mathrm{C}$. When feed was prepared every two to three days, using 60 L feed tank, one milliliter of trace solution per liter of feed was added.

Moreover, $12.5 \mathrm{mM}$ sodium hydroxide $(\mathrm{NaOH})$ solution was also separately prepared and fed to the FBR that helps to maintain alkaline pH (Le Corre et al., 2007; Guadie and Xia, 2012; Guadie et al., 2013). Depending on a specific experimental desire, the reactor pH was monitored by adjusting the $\mathrm{NaOH}$ pump frequency. Tap water was used to prepare the $\mathrm{NaOH}$ and feed solutions.

\subsection{Sludge source}

The reactor was inoculated with mixed liquor that was obtained from Quyang Wastewater Treatment Plant (aerobic/anoxic) (Shanghai, China). Before aerobic and anoxic samples were equally mixed, the fresh samples were characterized for $\mathrm{pH}$, MLSS and mixed liquor volatile suspended solids (MLVSS). The mean values of $\mathrm{pH}$, MLSS and MLVSS were found to be 6.4 $\pm 0.6,3.2 \pm 0.5 \mathrm{~g} / \mathrm{L}$ and $2.6 \pm 0.3 \mathrm{~g} / \mathrm{L}$ for aerobic and $6.8 \pm 0.2,3.0 \pm 0.4 \mathrm{~g} / \mathrm{L}$ and $2.3 \pm 0.1 \mathrm{~g} / \mathrm{L}$ for anoxic samples, respectively. In order to make the sludge source uniform, the mixtures were stored at $4^{\circ} \mathrm{C}$ using $20 \%$ glycerol. When the new running conditions were needed, the stored inoculum was acclimatized before feeding to the MBR.

\subsection{Reactor design and operations}

To evaluate nutrient removal from the synthetic wastewater, FBR (about 9.5 L) and two identical MBRs each with a total working volume of $8.4 \mathrm{~L}(0.3 \mathrm{~m} \times 0.1 \mathrm{~m} \times 0.28 \mathrm{~m}$ length $\times$ 
width $\times$ height) were constructed at Tongji University, Shanghai (Fig. 1). More detail specification about FBR can be found elsewhere (Guadie and Xia, 2012).

Fig. 1

In the FBR-MBR combo system, the FBR process was arranged first, suggesting FBR treatment can modify the wastewater characteristic and play a positive role to the MBR process. Feed and $\mathrm{NaOH}$ solutions were supplied continuously to the FBR at the bottom valves using peristaltic pumps (Longer Company, Baoding, China). When the solution was fluidized-up crossing the various areas, chemical reactions (nucleation and crystal growth) took place at the middle part of the reactor. Through time, the bigger precipitates settled down at the bottom section. They were collected by opening the lower valve once sufficient amount of crystals stored at the bottom part of the reactor. The liquid together with very fine precipitates were flow down from the top part of the FBR to the external recycler through plastic tube fitting. Portion of FBR treated effluent (through external recycler) was collected in supernatant tank while the rest was returned back to FBR.

The MBR system was designed to receive influent (i.e. FBR treated effluent) from the supernatant tank. A water level sensor was fitted on the auto-control board to keep a constant feed level for MBR system. The incoming wastewater (influent from supernatant) was further treated in the bioreactor using biological and physical methods. While microbial consortia play biodegradation activity and reduced the wastewater strength, membrane fibers play further physical filtration activity. Hollow fiber polyvinylidene fluoride (PVDF) membrane with an area of $200 \mathrm{~cm}^{2}$ and normal pore size of $0.1 \mu \mathrm{m}$ was used (Li-tree Company, Suzhou, China). Intermittent filtration with 10-minutes cycle (8 minutes filtration and 2 minutes pause) was 
employed. In addition, IAC (on/off) was made through an air diffuser (perforated tube) installed directly beneath the membrane module for supplying oxygen to microbial consortia, mixing the liquor, and scouring the membrane surface. The air flow in MBR was controlled at $8 \mathrm{~L} / \mathrm{h}$. The evolution of membrane fouling was monitored by the transmembrane pressure (TMP) development using pressure gauge (YN-60, Shanghai Weiken) fitted on the auto-control board.

\subsection{Experimental procedures}

In order to investigate the performance of FBR-MBR combo system for nutrient removal efficiency and membrane fouling reduction rate, the two MBRs were evaluated under constant $\left(\mathrm{MBR}_{\mathrm{C}}\right)$ and variable $\left(\mathrm{MBR}_{\mathrm{V}}\right)$ operating conditions. Based on the preliminary studies, the constant operating condition for FBR-MBR were $\mathrm{pH}_{\mathrm{FBR}}=9$, IAC (on/off)= 45/15 min, HRT= 6 $\mathrm{h}$ and flux $=70 \mathrm{~L} /\left(\mathrm{m}^{2} \mathrm{~h}\right)$. For FBR-MBR $\mathrm{V}_{\mathrm{V}}$, four experimental conditions were designs by varying $\mathrm{pH}_{\mathrm{FBR}}$, IAC, HRT and SRT. The ranges of each experimental conditions are listed in Table 1. The effect of $\mathrm{pH}$ on $\mathrm{MBR}_{\mathrm{V}}\left(\mathrm{FBR}-\mathrm{MBR}_{\mathrm{V}}\right)$ was carried out by monitoring the $\mathrm{pH}_{\mathrm{FBR}}$ from 7.5 to 9.5 with 0.5 unit scale difference. When the $\mathrm{pH}$ values varied, HRT and IAC of MBR $\mathrm{V}$ were maintained constant ( $6 \mathrm{~h}$ and 45/15 min, respectively). Different conditions of IACs (on/off=

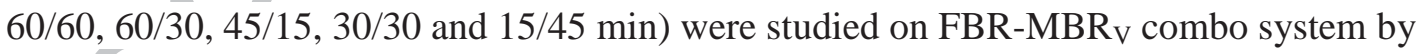
maintaining constant $\mathrm{pH}_{\mathrm{FBR}}(\mathrm{pH}=9)$ and $\mathrm{HRT}(\mathrm{HRT}=6 \mathrm{~h})$. The efficiency of simultaneous nitrification-denitrification (SND) process was calculated according to Eq. 2 (Third et al., 2003):

$$
S N D=\left(1-\frac{C_{N O_{x}^{-} \text {produced }}}{C_{N_{4}^{+}-\text {oxidized }}}\right) \times 100 \%
$$

where, $C_{\mathrm{NO}_{x}^{-}}=$concentration of $\mathrm{NO}_{3}{ }^{-}-\mathrm{N}$ and $\mathrm{NO}_{2}^{-}-\mathrm{N}$ produced, $\mathrm{C}_{\mathrm{NH}_{4}^{+}}=$concentration of $\mathrm{NH}_{4}{ }^{+}-\mathrm{N}$ oxidized during the reaction

Five HRTs (2, 4, 6, 8 and 10 h) were examined by applying different influent flow rates to 
$\operatorname{MBR}_{\mathrm{V}}$ (Eq. 3) while the $\mathrm{pH}_{\mathrm{FBR}}$ and the IAC were kept constant at 9 and 45/15 min, respectively.

For FBR (Eq. 4), the HRT was kept constant at 2 h (Guadie et al., 2013).

$$
\begin{gathered}
H R T_{M B R}=\frac{V}{Q i} \\
H R T_{F B R}=\frac{V}{Q i}
\end{gathered}
$$

where, $\mathrm{V}=$ working volumes of FBR and MBR, $\mathrm{Q}_{\mathrm{i}}=$ influent flow rates of FBR and MBR

For studying the effect of SRT on the nitrogen and phosphorous removal and membrane fouling, the two identical MBRs were operated parallel at different SRTs $\left(M_{B} R_{V}=10 \mathrm{~d}, 30 \mathrm{~d}, 60\right.$ $d$ and $\mathrm{MBR}_{\mathrm{C}}=$ without sludge withdrawal). For SRTs of 10, 30 and $60 \mathrm{~d}$, the experiments were run for 15, 45 and 90 days, respectively. Both MBRs were operated at constant operating conditions $\left(\mathrm{pH}_{\mathrm{FBR}}=9\right.$, IAC (on/off $)=45 / 15 \mathrm{~min}$ and $\left.\mathrm{HRT}=6 \mathrm{~h}\right)$.

All experiments were conducted at room temperature average $20.1 \pm 1.7{ }^{\circ} \mathrm{C}$. The initial MLSS concentration for $\mathrm{MBR}_{\mathrm{C}}$ and $\mathrm{MBR}_{\mathrm{V}}$ were $3.1 \pm 0.4$ and $3.0 \pm 0.7 \mathrm{~g} / \mathrm{L}$, respectively. Summary of most operating conditions are shown in Table 1.

\subsection{Analytic methods}

For chemical analysis, the influent and effluent samples were collected every two days from feed, supernatant, and effluent tanks. The constituents of orthophosphate-phosphorus $\left(\mathrm{PO}_{4}{ }^{3-}-\mathrm{P}\right)$, ammonium-nitrogen $\left(\mathrm{NH}_{4}{ }^{+}-\mathrm{N}\right)$, total Kjeldahl nitrogen (TKN), nitrite-nitrogen $\left(\mathrm{NO}_{2}{ }^{-}-\mathrm{N}\right)$, nitrate-nitrogen $\left(\mathrm{NO}_{3}{ }^{-}-\mathrm{N}\right)$, magnesium $(\mathrm{Mg})$, and calcium $(\mathrm{Ca})$ were analyzed according to standard methods (APHA et al., 1998). $\mathrm{PO}_{4}{ }^{3-}-\mathrm{P}$ and $\mathrm{NH}_{4}{ }^{+}-\mathrm{N}$ were analyzed using UV-visible spectrophotometer (UV-2700, Shimadzu, Japan) while Mg and Ca were measured using flame atomic absorption spectrophotometer (PE-AA400, Perkin Elmer, USA). For crystal purity 
analysis, inductively coupled plasma-optimal emission spectrophotometer (ICP-OES)

(ICP-720ES, Agilent, USA) was used to quantify Mg, Ca, iron (Fe), aluminum (Al), potassium (K) and sodium $(\mathrm{Na})$ together.

Dissolved oxygen (DO), pH and turbidity were measured using DO meter (HQ4d, HACH USA), pH meter (PHS-29A, HACH, USA) and turbidimeter (2100N, HACH, USA), respectively. The MLSS and MLVSS samples were measured according to standard methods (APHA et al., 1998). The membrane fouling was observed using scanning electron microscope (SEM) (XL-30, Philips, Netherlands). Moreover, the SEM coupled with energy diffractive spectrometer (SEM-EDS) was also used to characterize the crystal harvested in the FBR. Crystal products were also characterized using x-ray diffractometer (XRD).

Sludge characteristics in terms of SMP and EPS were extracted according to Kornboonraksa et al. (2009) with some modifications. Soluble microbial product solutions were extracted by centrifuging $40 \mathrm{~mL}$ of mixed liquor sample at $6000 \mathrm{~g}$ for $5 \mathrm{~min}$ and by filtering the solution through a $0.45 \mu \mathrm{m}$ polyether sulfone syringe filter (Anpel Compny, Shanghai, China). The remaining pellet was washed and resuspended with $40 \mathrm{~mL}$ of saline solution $(0.85 \% \mathrm{NaCl})$. Subsequently, the resuspended solution was extracted by heating at $80{ }^{\circ} \mathrm{C}$ for $30 \mathrm{~min}$. Finally, EPS solutions were extracted by centrifuging the biomass at $12000 \mathrm{~g}$ for $20 \mathrm{~min}$ and by filtering the solution through a $0.45 \mu \mathrm{m}$ polyether sulfone syringe filter. Although the SMP and EPS contain highly complex organic molecules, carbohydrates and proteins were used to quantify and better characterize them as stated in many literatures (Trussell et al., 2006; Kornboonraksa et al., 2009). Measurement of protein concentrations was carried out by Lowry methods (Lowry et al., 1951). Phenol-sulfuric acid method was used for carbohydrate determination (Dubois et al., 
1956). Total organic carbon (TOC) was measured using TOC analyzer (TOC-VCPN Shimadzu, Japan).

\subsection{Membrane cleaning procedures}

Membrane cleaning has been made with water and chemicals either at the end of each experiment or when the TMP reaches $15 \mathrm{inHg}(\sim 50 \mathrm{kPa})$. To perform the cleaning activity, the membrane was thoroughly rinsed with distilled water to remove cake formation on the membrane surface. Then, the membrane was soaked in $1 \mathrm{M} \mathrm{NaOH}$ and $1 \%$ sodium hypochlorite ( $\mathrm{NaOCl}$ ) mixed solution for $12 \mathrm{~h}$. After the membrane was thoroughly rinsed with water to remove the residual chemicals, it was submerged in $0.2 \mathrm{~N} \mathrm{HNO}_{3}$ solutions for $12 \mathrm{~h}$. Finally, the membrane was thoroughly rinsed again with distilled water to remove acid solution. During the cleaning of fouled membrane, another membrane was replaced in order to operate MBR process continuously.

Table 1

\section{Results and discussion}

In traditional nutrient treatment approach, while phosphorus successively removed in anaerobic-aerobic system, nitrogen typically requires aerobic-anoxic bioreactor configurations (Xia et al., 2010). This opposite reactor configuration makes simultaneous phosphorus and nitrogen treatment more difficult (Qiu et al., 2010). In this study, the FBR-MBR combo system played a significant role in modifying the wastewater characteristic, achieving simultaneous phosphorus and nitrogen removal, and reducing membrane fouling rate (discussed in section 3.1 and 3.2).

\subsection{FBR-MBR ${ }_{C}$ combo system performance}


In order to evaluate the FBR-MBR combo system under constant operating conditions, $\mathrm{MBR}_{\mathrm{C}}$ was kept constant at $\operatorname{HRT}_{\mathrm{FBR}}(2 \mathrm{~h}), \operatorname{HRT}_{\mathrm{MBR}}(6 \mathrm{~h}), \mathrm{IAC}$ (on/off= 45/15 min) and extended/infinite SRT. When the FBR treated effluent was collected and feed to the MBR system, the organic load (COD) was decreased about two orders of magnitude from its original concentration (i.e. decreased from 250-325 mg/L to 170-225 mg/L) (Table 1). The reduced organic load helped to achieve excellent effluent quality $\left(\mathrm{COD}=2.1 \pm 0.8, \mathrm{NH}_{4}{ }^{+}-\mathrm{N}=0.6 \pm 1.0, \mathrm{PO}_{4}{ }^{3-}-\mathrm{P}=0.87 \pm 0.5\right.$ and turbidity= 0.12-0.34 NTU), minimize TMP development (less than 7 inHg), and stabilize biomass concentration (Table 1). The MLSS and MLVSS concentrations varied from 3.0 to 5.0 g/L and 2.5 to $4.6 \mathrm{~g} / \mathrm{L}$, respectively. The ratio of MLVSS to MLSS concentration in the MBR system was found to be constant within the range of $0.80-0.95$ (average $0.92 \pm 0.04$ ), but was slightly higher than that of the conventional activated sludge process that typically ranges from 0.75 to 0.80 (Stephenson et al., 2000; Metcalf and Eddy, 2003). This indicated that the FBR-MBR $\mathrm{C}_{\mathrm{C}}$ combo system modify the wastewater characteristic (i.e. inorganic components were precipitated in the FBR and therefore did not accumulate in the MBR system). This condition offers the combo system to maintain stable MLSS concentration.

As shown in Fig. 2, when the FBR was operated alone, the $\mathrm{PO}_{4}{ }^{3-}-\mathrm{P}$ removal was found higher $(>80 \%)$ than the removal efficiency of $\mathrm{NH}_{4}{ }^{+}-\mathrm{N}(<40 \%)$ and COD $(<30 \%)$. However, the COD and $\mathrm{NH}_{4}{ }^{+}-\mathrm{N}$ removal efficiency of MBR alone without FBR was found significant ( $\left.>90 \%\right)$ than $\mathrm{PO}_{4}{ }^{3-}-\mathrm{P}$ removal efficiency $(<20 \%)$. Interestingly, the combo system played a significant role in narrowing down these differences to less than $10 \%$ (i.e. $92.6 \pm 4.2,98.7 \pm 1.2$ and $99.3 \pm 0.5 \%$ removal efficiency for $\mathrm{PO}_{4}{ }^{3-}-\mathrm{P}, \mathrm{NH}_{4}{ }^{+}-\mathrm{N}$ and COD, respectively) (Fig. 2). The efficient simultaneous $\mathrm{NH}_{4}{ }^{+}-\mathrm{N}$ and COD removal observed in the system was due to the co-existence of 
heterotrophic and autotrophic microbes in the bioreactor which was consistent with the results of Kornboonraksa et al. (2009). Nitrogen removal was carried out through the biological oxidation and reduction processes which are typically performed by the autotrophic nitrobacteria and heterotrophic denitrifiers, respectively (Anup et al., 2011).

\section{Fig. 2}

As shown in Fig. 3, microbes governing the subsequent conversion of $\mathrm{NH}_{4}^{+}-\mathrm{N}$ to $\mathrm{NO}_{2}{ }^{-}-\mathrm{N}$ and $\mathrm{NO}_{3}{ }^{-}-\mathrm{N}$ (ammonia and nitrite oxidizing bacteria) initially seemed quiescent. However, after five weeks of operation, the sludge became active and showed a significant decrease of $\mathrm{NH}_{4}{ }^{+}-\mathrm{N}$ and TKN concentrations. Throughout the entire experimental period, the influent concentrations were showed fluctuation between 45-55 (average 51.6 \pm 3.8 ) $\mathrm{mg} / \mathrm{L}$ for $\mathrm{NH}_{4}{ }^{+}-\mathrm{N}$ and between 60-75 (average 66.2 \pm 6.0 ) $\mathrm{mg} / \mathrm{L}$ for TKN. After 40 days of operation, the effluent concentration for $\mathrm{NH}_{4}{ }^{+}-\mathrm{N}$ and TKN were found less than $1 \mathrm{mg} / \mathrm{L}$ and it was almost stable (Fig. 3). After five weeks of reactor operation, the $\mathrm{NH}_{4}{ }^{+}-\mathrm{N}$ and $\mathrm{TKN}$ average removal efficiencies were also found greater than 96\% (Fig. 3). Moreover, after the combo system achieved efficient and stable ammonia removal, the SND efficiency was found in between $78 \%$ and $92 \%$ (average $87 \pm 2.0 \%$ ) (Table 1). Throughout the entire operation, the concentration of $\mathrm{NO}_{2}{ }^{-}-\mathrm{N}$ was also very low (0.06-0.20 mg/L), suggesting that nitrite was not accumulated in the MBR system (i.e. the combo system provides a suitable niche for nitrite oxidizing bacteria that plays a significant role in nitrite conversion to nitrate) (Table 1). However, a wide range of $\mathrm{NO}_{3}{ }^{-}-\mathrm{N}$ concentration results (5.0-40.0 mg/L) observed the average was found less than $10 \mathrm{mg} / \mathrm{L}$ also suggested that the SND activities had been occurred in the reactor. In general, the efficient removal of $\mathrm{NH}_{4}{ }^{+}-\mathrm{N}$ and relatively higher SND activity observed in the combo system might at least be related to i) low 
level of DO that deteriorated during pausing the air diffusing pump ii) incomplete air circulation in the reactor iii) presence of biofilms which create a shield for denitrifiers. The presence of an anoxic microzone in the biofilm could result SND in the reactor that helps nitrification occurs on the surface of the biofilm, whereas denitrification occurs in the inner layers due to a DO gradient within the biofilm (Ding et al., 2011; Wang et al., 2012).

Generally, DO concentrations greater than $2 \mathrm{mg} / \mathrm{L}$ is essential to maintain complete nitrification in biological wastewater treatment plant (Trussell et al., 2006; Holakoo et al., 2007; Wang et al., 2012). Nevertheless, the DO level obtained in this study was not the limiting factor for the SND process. During IAC (on/off= 45/15 min), the DO concentration was between 2-6 mg/L and 0.25-2 mg/L. Anup et al. (2011) reported that an average $2.5 \mathrm{mg} / \mathrm{L}$ DO during aeration cycle and $0.95 \mathrm{mg} / \mathrm{L}$ during non-aeration cycle could obtain efficient SND removal. Wang et al. (2012) also achieved efficient SND process when they maintained the DO level between 1.0-1.5 $\mathrm{mg} / \mathrm{L}$ for aerobic cycle and $0.5 \mathrm{mg} / \mathrm{L}$ for anoxic cycle.

Fig. 3

It was first assumed that the FBR would increase the $\mathrm{pH}$ of the MBR and influence microbial communities in the reactor because of its higher working $\mathrm{pH}$. However, the combo system was working in harmony without any $\mathrm{pH}$ adjustment (Table 2). In order to crystalize the incoming phosphorus and nitrogen as struvite, the system needs alkaline $\mathrm{pH}$ (i.e. $\mathrm{pH}$ in FBR maintained $\geq 9$ with $\mathrm{NaOH}$ solution). Fattah et al. (2008) stated that the recommended $\mathrm{pH}$ range for struvite formation is between 8 and 10. Le Corre et al. (2007) and Guadie and Xia (2012) were also observed pure struvite quality at pH 9 and 9-9.5, respectively. After FBR treatment, the solution $\mathrm{pH}$ was found to be $8.76 \pm 0.57$ in the supernatant tank, which was slightly lower than the 
$\mathrm{pH}$ in the FBR. This could be most related to struvite formation that has been observed at the middle part of the FBR, thereby increasing the hydrogen ion $\left(\mathrm{H}^{+}\right)$concentrations and modify the FBR effluent (Eq. 2). Moreover, IAC also played a significant role in modifying the $\mathrm{pH}$ in the MBR system. For instance $\left(\mathrm{MBR}_{\mathrm{C}}\right)$, when the $\mathrm{pH}$ was measured under non-aeration cycle (IAC= off) and aeration cycle $(\mathrm{IAC}=$ on), the results were exhibited statistically significant difference (p-value $=6.63 \mathrm{E}-21<0.05$ ) with $\mathrm{pH}$ of $7.73 \pm 0.50$ and $7.25 \pm 0.59$, respectively (Table 2$)$. This was due to the biodegradation of complex organic compounds (such as starch, glucose, urea and peptone) added as a feed was converted to simple organic acids and decreased the $\mathrm{pH}$ value. The final effluent $\mathrm{pH}$ (7.45 for $\mathrm{MBR}_{\mathrm{C}}$ and 7.30 for $\mathrm{MBR}_{V}$ ) were in the range of $\mathrm{pH}$ discharge limit set by many countries (6-9).

Normally, during nitrification process, $\mathrm{NH}_{4}{ }^{+}-\mathrm{N}$ oxidation is accompanied with hydrogen ions $\left(\mathrm{H}^{+}\right)$release thereby causing $\mathrm{pH}$ drop in the system. It has been widely documented in literature that nitrification efficiency highly depends on the solution $\mathrm{pH}$ (Metcalf and Eddy, 2003; An et al., 2007; Anup et al., 2011). As a result, sodium bicarbonate $\left(\mathrm{NaHCO}_{3}\right)$ as an extra alkaline source has been added for most studies to maintain stable $\mathrm{pH}$ condition (Trussell et al., 2006; Holakoo et al., 2007; Anup et al., 2011). In this study, self-balanced pH was observed as IAC offered a special advantage for the combo system to maintain the nitrifying and denitrifying bacterial communities in a single reactor without addition of extra alkaline and nutrient sources. This was in line with the report of Wang et al. (2012).

Table 2

In order to figure out more about the importance of the combo system (FBR-MBR ${ }_{C}$ ) on membrane fouling, the MBR systems were evaluated with and without FBR at constant 
operating conditions ( $\mathrm{pH}=9, \mathrm{HRT}=6 \mathrm{~h}$, and $\mathrm{IAC}=45 / 15 \mathrm{~min})$. As shown in Fig. 4, combining the MBR system with FBR played a significant role in reducing membrane fouling rate. When the MBR system received raw wastewater directly from the feed tank (MBR-without FBR), the TMP increase was sharp and significant (i.e. increasing of TMP from 0.5 to over $15 \mathrm{inHg}$ at 26, 42 and $51 \mathrm{~d}$ ). However, the TMP rise was insignificant (less than $7 \mathrm{inHg}$ ) when the MBR system gets feed from FBR treated effluent/supernatant tank ( FBR-MBR ${ }_{C}$ ) (Fig. 4). The results clearly revealed that the wastewater characteristics that favor membrane fouling (i.e. organic load, phosphorus and nitrogen, etc.) has been significantly altered through FBR treatment.

As shown in Fig. 4, when the TMP value increased to 15 inHg and above, the membrane was washed with water and chemicals. After cleaning, the TMP dropped dramatically and the filtration capacity of the membrane was almost fully recovered, which indicated that the foulants (i.e. organic and inorganic matter, and microorganisms) were removed by the physical and chemical cleaning agent on the surface of membrane. The SEM images of fouled membrane surfaces were taken before and after cleaning and compared with the virgin membrane. The SEM image of the virgin hollow-fiber membrane surface was porous and free of particles. However, the SEM images taken before cleaning were not clear (i.e. the membrane pores were covered with thick cake layer). After cleaning, the membrane pores were relatively visible.

\section{Fig. 4}

The performances of the FBR-MBR ${ }_{C}$ combo system was compared with other studies (Table 3). However, the purpose of most differ from this study, there has been previous studies combining the MBR system with other systems (Guo et al., 2009; Kornboonraksa et al., 2009; Yang et al., 2009; Ng et al., 2011; Phattaranawik and Leiknes, 2011; Nguyen et al., 2013). For 
instance, Kornboonraksa et al. (2009) tried to combine chemical precipitation with MBR (CP-MBR) treatment to reduce total suspended solid from the piggery wastewater. The combined system was efficient for COD (99.4\%) and $\mathrm{NH}_{4}{ }^{+}-\mathrm{N}$ (98.2\%) removal, but the removal efficiency of phosphorus was not mentioned (Table 3). Ng et al. (2011) were also employed Bio-entrapped carrier before MBR system to treat food wastewater, but only COD removal efficiency has been reported. The study carried out by Guo et al. (2009) on sponge combined with MBR system (Sponge-MBR) showed efficient removal of COD (>96\%), $\mathrm{NH}_{4}{ }^{+}-\mathrm{N}(>99 \%)$ and $\mathrm{PO}_{4}{ }^{3-}-\mathrm{P}$ (>98.8\%), which was in line with this study reporting about $\mathrm{PO}_{4}{ }^{3-}-\mathrm{P}$. Xia et al. $(2008,2010)$ were also used MBR systems alone for the treatment of synthetic and bathing wastewater. Although they achieved high COD (94\%-99\%) and $\mathrm{NH}_{4}{ }^{+}-\mathrm{N}$ (93\%-96.9\%) removal efficiency, phosphorus removal has not been reported. As can be seen from Table 3, treatment approaches that employ MBR system have been found rarely mentioned about $\mathrm{PO}_{4}{ }^{3-}-\mathrm{P}$ removal. Opposed to MBR systems, studies carried out using FBR treatment achieved efficient $\mathrm{PO}_{4}{ }^{3-}-\mathrm{P}$ removal, but most lacks comprehensive information about COD and $\mathrm{NH}_{4}{ }^{+}-\mathrm{N}$ removal efficiency (Munch and Barr, 2001; Adnan et al., 2003; Le Corre et al., 2007; Fattah et al., 2008; Pastor et al., 2008; Guadie et al., 2013). However, in this study, employing the FBR-MBR combo system significantly enhanced the simultaneously removal of COD (99.3\%), $\mathrm{NH}_{4}{ }^{+}-\mathrm{N}(98.7 \%)$ and $\mathrm{PO}_{4}{ }^{3-}-\mathrm{P}(93 \%)$ (Table 3). More interestingly, the phosphorus and nitrogen removed in the FBR system could be recovered as struvite (that was confirmed with SEM-EDS, XRD) and made this study more preferable than others.

Analysis of a typical sample of SEM image ( Supplementary data Fig. Sa) and the EDS spectrum (Supplementary data Fig. Sb) confirmed that the crystal harvested in the FBR was 
struvite. The EDS depicted that the elements such as oxygen, magnesium and phosphorus with weight percentages of the peaks about 56.13\%, 19.78\% and 23.47\%, respectively. However, EDS was not sensitive to nitrogen, the major peaks and positions observed fit well the standard struvite peak and position, which was further confirmed with XRD (Supplementary data Fig. Sc). As the struvite recovered can be used directly as slow released fertilizer (Munch and Barr, 2001), the idea of recovering struvite from sewage might be a sustainable approach which deals environmental, societal and economic issues. Particularly, the approach is more viable for sustaining phosphorus supply that has no current known substitutes.

Table 3

\subsection{FBR-MBR ${ }_{V}$ combo system performance at different $\mathrm{pH}, \mathrm{HRT}$, SRT and IAC}

To illustrate more detail about the FBR-MBR combo system performance (removal efficiency and membrane fouling), different factors including $\mathrm{pH}_{\mathrm{FBR}}$, HRT, SRT, and IAC were investigated. Figure 5 shows the effect of $\mathrm{pH}_{\mathrm{FBR}}$, HRT and SRT on phosphorus, nitrogen and COD removal efficiency.

Fig. 5

\subsubsection{Effect of $\mathrm{pH}_{\mathrm{FBR}}$}

Increasing the $\mathrm{pH}_{\mathrm{FBR}}$ from 7.5 to 9.5 improved the $\mathrm{PO}_{4}{ }^{3-}-\mathrm{P}$ treatment efficiency from $43 \%$ to 94\% for FBR and 25\% to 96\% for FBR-MBR ${ }_{V}$ combo system, respectively (Fig. 5a).

Surprisingly at lower $\mathrm{pH}$ values, the FBR system alone showed greater $\mathrm{PO}_{4}{ }^{3-}$-P removal efficiency than the combo system. Although the mechanism needs further detail investigation, the reason might be associated with i) the washed-out phosphorus precipitate from FBR effluent might reach to $\mathrm{MBR}$ and dissolve at lower $\mathrm{MBR} \mathrm{pH}(\mathrm{pH}<7)$ (Pastor et al., 2008); ii) phosphate degrading microbes might be outcompeted by other microbes at lower $\mathrm{pH}$ in the MBR (Filipe et 
al., 2001); and iii) the microbial cell lysis (Pollice et al., 2008).

Studies showed that struvite crystallization was highly pH dependent (Adnan et al., 2003; Le Corre et al., 2007; Guadie et al., 2013). Pastor et al. (2008) stated that struvite is soluble under acidic condition and insoluble at alkaline $\mathrm{pH}$ which was in line with this study. Moreover, Filipe et al. (2001) stated that the competition between phosphate accumulating and glycogen accumulating organisms was $\mathrm{pH}$ sensitive. Glycogen accumulating organisms could lose the competitive advantages when the $\mathrm{pH}$ rises. Hence, $\mathrm{pH}$ greater than 7.25 was necessary to keep a good phosphate accumulating organism (Filipe et al., 2001). In this study, when the $\mathrm{pH}_{\mathrm{FBR}}$ increased up to 8.5 or higher, the $\mathrm{pH}$ in supernatant tank and MBR became greater than 8 and 7 , respectively.

The impact of $\mathrm{pH}$ was moderate for $\mathrm{COD}$ and $\mathrm{NH}_{4}{ }^{+}-\mathrm{N}$ removal, especially in the $\mathrm{FBR}$ (30\%-40\% and 26\%-53\%, respectively). For the FBR-MBR $\mathrm{V}_{\mathrm{V}}$ combo system, the removal efficiency was $94.2 \%-99.8 \%$ for COD and $82 \%-99 \%$ for $\mathrm{NH}_{4}{ }^{+}-\mathrm{N}$ (Fig. 5a). Slightly higher $\mathrm{NH}_{4}{ }^{+}-\mathrm{N}$ removal efficiency was observed in FBR treatment at pH 9.5 which was owing to the conversion from $\mathrm{NH}_{4}{ }_{4}-\mathrm{N}$ to ammonium gas that escaped from the reactor (Le Corre et al., 2007; Fattah et al., 2008; Guadie et al., 2013). The results of increasing pH associated an increased $\mathrm{NH}_{4}{ }^{+}-\mathrm{N}$ and $\mathrm{PO}_{4}{ }^{3-}-\mathrm{P}$ removal efficiency indicated that phosphorus and nitrogen forms a crystal (struvite) at higher $\mathrm{pH}$.

As shown in Fig.6a, the effect of $\mathrm{pH}$ on membrane fouling (TMP= $25.6 \mathrm{inHg}$ ) was significant at lower $\mathrm{pH}$ value $(\mathrm{pH}=7.5)$, which was associated with high EPS carbohydrate $\left(\right.$ EPS $\left._{C}\right)$ concentration $(96.2 \mathrm{mg} / \mathrm{L})$. The effect of elevated $\mathrm{EPS}_{\mathrm{C}}$ concentration on membrane fouling rate was also reported in other studies (Trussell et al., 2006; Kornboonraksa et al., 2009). 
However, elevated EPS protein $\left(\mathrm{EPS}_{\mathrm{P}}\right)$ and SMP protein $\left(\mathrm{SMP}_{\mathrm{P}}\right)$ concentration has been noticed in Fig. 6a-d, the value at various $\mathrm{pH}$ and other operating conditions (HRT, SRT and IAC) seemed almost constant (i.e. $\mathrm{EPS}_{\mathrm{P}}$ and $\mathrm{SMP}_{\mathrm{P}}$ varied between $41-48 \mathrm{mg} / \mathrm{L}$ and 18-23 mg/L, respectively), and might not have significant influence on membrane fouling. Moreover, at lower pH slightly higher MLSS concentration (8.5 g/L) was observed that indirectly confirmed inorganic ions were higher part of the MLSS that might contributed to the TMP increase and fast membrane fouling. On the other hand, struvite precipitation could reduce inorganic ions (such as, phosphate and ammonium) thereby reducing the MLSS concentration and membrane fouling rates. As shown in Fig. $6 \mathrm{a}$, at $\mathrm{pH} \geq 8.5$, the MLVSS concentrations and TMP values were almost the same (i.e. vary between 3.2-3.5 g/L and 4.0-4.2 inHg, respectively).

Fig. 6

\subsubsection{Effect of HRT}

The effect of HRT was investigated by varying HRT from 2 to $10 \mathrm{~h}$ with $2 \mathrm{~h}$ interval. As shown in Fig. 5b, the change of HRT values did not significantly altered the removal efficiency of $\mathrm{PO}_{4}{ }^{3-}-\mathrm{P}$ (80 to 85\%), $\mathrm{NH}_{4}{ }^{+}-\mathrm{N}$ (95 to 99\%) and COD (97 to 99.5\%). However, the effect of HRT was prominent on membrane fouling. Higher TMP (24.8 inHg) was observed at $2 \mathrm{~h}$ than $10 \mathrm{~h}$ (4.4 inHg) most likely associated with EPS $_{\mathrm{C}}$ (Fig. 6b). This is because, reduction in HRT from $10 \mathrm{~h}$ to $2 \mathrm{~h}$ increased EPS carbohydrate from 25 to $70 \mathrm{mg} / \mathrm{L}$. Similar results were presented in other studies. Meng et al. (2007) stated that the HRT did not change the removal of COD, but HRT was a factor of membrane fouling. Cho et al. (2005) also reported that MBR operation at longer HRT reduced the membrane fouling rate.

\subsubsection{Effect of SRT}


The impact of SRT was found to be insignificant for COD and moderate for $\mathrm{NH}_{4}{ }^{+}-\mathrm{N}$ (Fig. 5c). With SRT variation of 10 to $60 \mathrm{~d}, \mathrm{NH}_{4}{ }^{+}-\mathrm{N}$ and COD removal efficiency varied from $90 \%$ to 98\% and $98.6 \%$ to $99.7 \%$, respectively. On the other hand, variation of SRT showed a slight effect on $\mathrm{PO}_{4}{ }^{3-}-\mathrm{P}$ removal efficiency (Fig. 5c). When the SRT increased from 10 to $30 \mathrm{~d}$, the $\mathrm{PO}_{4}{ }^{3-}-\mathrm{P}$ removal efficiency were increased from 85 to $96 \%$. Further increasing of the SRT beyond $30 \mathrm{~d}$ slightly decreased the phosphorus removal efficiency, which was due to high biomass accumulations and cell lysis in the bioreactor (Holakoo et al., 2007; Pollice et al., 2008; Kornboonraksa et al., 2009). As shown in Fig. 6c, the longer the SRT, the more biomass was retained in the MBR (i.e. $3.5,4.4$ and $6.1 \mathrm{~g} / \mathrm{L}$ MLSS were observed for SRT 10 , 30 and $60 \mathrm{~d}$, respectively). However, the elevated MLSS concentration was not found the cause of membrane fouling, which was similar to other studies (Trussell et al., 2006; Kornboonraksa et al., 2009) that stated MLSS ranging from 4 to $8 \mathrm{~g} / \mathrm{L}$ had no significant effect on membrane fouling rate.

The TMP profile at shorter SRT (10 d) showed fast membrane fouling rate which was coupled with the higher EPS ${ }_{C}$ concentration (Fig.6c). Increasing the SRT from 10 to $60 \mathrm{~d}$ decreased the EPS concentration from $78.4 \mathrm{mg} / \mathrm{L}$ to $26.5 \mathrm{mg} / \mathrm{L}$ and the TMP from $28.9 \mathrm{inHg}$ to 5.6 inHg, respectively. Similar results were reported in other studies (Ahmed et al., 2007; Kornboonraksa et al., 2009; Ng et al., 2011). They addressed that slow growing microorganisms were found to grow well at long SRT, which were more capable of consuming macromolecules such carbohydrate and protein as substrates and producing less biopolymers, leading to reduce membrane fouling rate.

\subsubsection{Effect of intermittent aeration}

In order to investigate the effect of intermittent aeration, five on/off aeration cycles (60/60, 
60/30, 45/15, 30/30 and 15/45 min) were examined at optimum conditions of $\mathrm{pH}_{\mathrm{FBR}}(9), \mathrm{HRT}_{\mathrm{FBR}}$ (2 h) and $\mathrm{HRT}_{\mathrm{MBR}}(6 \mathrm{~h})$. The DO concentrations during “on" and "off” aeration cycles were ranged from 0.8 to $6.3 \mathrm{mg} \mathrm{O}_{2} / \mathrm{L}$ and 0.2 to $3.0 \mathrm{mg} \mathrm{O}_{2} / \mathrm{L}$, respectively (Table 4). Varying the on/off condition showed little effect on phosphorus removal (90\% to 95\%), but was considerable to nitrogen (63-99\%) and COD (78\%-99\%) removal. Under extended "off" and shorter aeration condition (i.e. $15 / 45 \mathrm{~min}$ ), the level of DO was as low as 0.2 to $0.8 \mathrm{mg} / \mathrm{L}$, which showed moderate $\mathrm{NH}_{4}{ }^{+}-\mathrm{N}$ and COD removal (about 63\% and 78\%, respectively). In the reverse condition (45/15 min), the reduction of $\mathrm{NH}_{4}{ }^{+}-\mathrm{N}$ and COD was almost complete as the DO level was not limiting (1.4-3.1 mg/L). Although extending the aeration cycle higher than 45 min could help to maintain complete removal efficiency, the condition was found to be disturbing the sludge floc structure developed in the MBR system. Since excellent removal efficiency was obtained at 45/15 min on/off aeration cycle, this level has been considered as an optimum IAC based on energy saving.

Table 4

Regarding membrane fouling, the TMP was higher (26.5 inHg) at lower aeration cycle than extended (4.4 inHg) because the highest $\mathrm{EPS}_{\mathrm{C}}(66.8 \mathrm{mg} / \mathrm{L})$ and TOC $(141 \mathrm{mg} / \mathrm{L})$ were observed at 15/45 min aeration cycle (Fig. 6d). At lower aeration cycle, the level of DO was less than 1 mg/L (Table 4), suggesting poor organic biodegradation (which implies high organic load accumulation) that might cause the fast membrane fouling rate observed. Studies showed that higher organic load accumulation in the MBR system positively correlated with fast membrane fouling rate (Trussell et al., 2006).

\section{Conclusions}

In this study, the novel FBR-MBR combo system has shown certain unique features. Firstly, 
combing the FBR with MBR was proved to work in harmony without any $\mathrm{pH}$ adjustment.

Secondly, efficient removal of nutrients $\left(\mathrm{PO}_{4}{ }^{3-}-\mathrm{P}=92.6 \pm 4.2 \%\right.$ and $\left.\mathrm{NH}_{4}{ }^{+}-\mathrm{N}=98.7 \pm 1.2 \%\right)$, organic matter $(\mathrm{COD}=99.3 \pm 0.5 \%)$, and SND activities (87.0 $\pm 2.0 \%)$ were achieved when the MBR received feed from the FBR effluent. Thirdly, membrane fouling was mitigated when the combo system was operated at optimum operating conditions of $\mathrm{pH}_{\mathrm{FBR}}$ 9, HRT 6 h and IAC 45/15 min. Fourthly, phosphorus recycle as struvite from FBR at low concentration $\left(\mathrm{PO}_{4}{ }^{3-}-\mathrm{P}=12.5 \mathrm{mg} / \mathrm{L}\right)$ was confirmed.

\section{Acknowledgements}

This work was supported by the Fundamental Research Funds for the Central Universities, Shanghai Shuguang Tracking Program (No. 10GG12), the High-Tech Research and Development Program (863) of China (No. 2009AA062902), and $1^{\text {st }}$ World Membrane Bioreactor (MBR) Centre.

\section{References}

Adnan, A., Mavinic, D.S., Koch, F.A., 2003. Pilot-scale study of phosphorus recovery through struvite crystallization-examining the process feasibility. Journal of Environmental Engineering and Science 2(5), 315-324.

Ahmed, Z., Cho, J., Lim, B.R., Song, K.G., Ahn, K.H., 2007. Effects of sludge retention time on membrane fouling and microbial community structure in a membrane bioreactor. Journal of Membrane Science 287(2), 211-218.

An, J.Y., Kwon, J.C., Ahn, D.W., Shin, D.H., Shin, H.S., Kim, B.W., 2007. Efficient nitrogen removal in a pilot system based on upflow multi-layer bioreactor for treatment of strong nitrogenous swine wastewater. Process Biochemistry 42(5), 764-772.

Anup, G., Woo-Chang, K., Sang-Eun, O., 2011. Removal of nitrogen from anaerobically digested swine wastewater using an anoxic/oxic (A/O) process complemented with a sulfur-packed biofilter. African Journal of Biotechnology $10(48$ ), 9831-9838. 
APHA, AWWA, WEF, 1998. Standard methods for the examination of water and wastewater, 20th ed. American Public Health Association, Washington DC, USA.

Cho, J., Song, K.G., Lee, H.S., Ahn, K.H., 2005. Sequencing anoxic/anaerobic membrane bioreactor (SAM) pilot plant for advanced wastewater treatment. Desalination 178(1-3), 219-225.

de-Bashan, L.E., Basha, Y., 2004. Recent advances in removing phosphorus from wastewater and its future use as fertilizer (1997-2003). Water Research 38(19), 4222-4246.

Ding, D., Feng, C., Jin, Y., Hao, C., Zhao, Y., Suemura, T., 2011. Domestic sewage treatment in a sequencing batch biofilm reactor (SBBR) with an intelligent controlling system. Desalination 276(1-3), 260-265.

Dubois, M., Gilles, K.A., Hamilton, J.K., Rebers, P.A., Smith, F., 1956. Colorimetric method for determination of sugars and related substances. Analytical Chemistry 28(3), 350-356.

Fattah, K., Mavinic, D.S., Koch, F.A., Jacob, C., 2008. Determining the feasibility of phosphorus recovery as struvite from filter press centrate in a secondary wastewater treatment plant. Journal of Environmental Science and Health, Part A 43(7 ), 756-764.

Filipe, C.D.M., Daigger, G.T., Grady, C.P.L., 2001. Effects of pH on the rates of aerobic metabolism of phosphateaccumulating and glycogen-accumulating organisms. Water Environmental Research 73(2), 213-222.

Fu, Z., Yang, F., Zhou, F., Xue, Y., 2009. Control of COD/N ratio for nutrient removal in a modified membrane bioreactor (MBR) treating high strength wastewater. Bioresource Technology 100 (1), 136-141.

Guadie, A., Xia, S., 2012. Evaluating factors affecting phosphorus removal and recovery from wastewater using fluidized bed reactor. In: Proceeding of the 12th Sustainable Water Resources Development Symposium, 26-27 June 2012, AMU, Ethiopia. A special issue on Ethiopian Journal of Water Science and Technology 12(1), 60-70.

Guadie, A., Xia, S., Jiang, W., Zhou, L., Zhang, Z., Hermanowicz, S.W., Xu, X., Shen, S., 2013. Enhanced struvite recovery from wastewater using a novel cone-inserted fluidized bed reactor. Journal of Environmental Sciences, in press.

Guo, W., Ngo, H.H., Palmer, C.G., Xing, W., Hu, A.Y.J., Listowski, A., 2009. Roles of sponge sizes and membrane types in a single stage sponge-submerged membrane bioreactor for 
improving nutrient removal from wastewater for reuse. Desalination 249 (2), 672-676. Holakoo, L., Nakhla, G., Bassi, A.S., Yanful, E.K., 2007. Long term performance of MBR for biological nitrogen removal from synthetic municipal wastewater. Chemosphere 66(5), 849-857.

Kornboonraksa, T., Lee, H.S., Lee, S.H., Chiemchaisri, C., 2009. Application of chemical precipitation and membrane bioreactor hybrid process for piggery wastewater treatment. Bioresource Technology 100(6), 1963-1968.

Le Corre, K.S., Valsami-Jones, E., Hobbs, P., Parsons, S.A., 2007. Impact of reactor operation on success of struvite precipitation from synthetic liquors. Environmental Technology 28(11), 1245-1256.

Lowry, O.H., Rosebrough, N.J., Farr, A.L., Randall, R.J., 1951. Protein measurement with the folin phenol reagent. Journal of Biological Chemistry 193(1), 265-275.

Meng, F., Shi, B., Yang, F., Zhang, H., 2007. Effect of hydraulic retention time on membrane fouling and biomass characteristics in submerged membrane bioreactors. Bioprocess and Biosystems Engineering 30(5), 359-367.

Metcalf, Eddy, 2003. Wastewater Engineering:Treatment and Reuse, fourth Ed. McGraw-Hill , New York.

Munch, E.V., Barr, K., 2001. Controlled struvite crystallization for removing phosphorus from anaerobic digester sidestreams. Water Research 35(1 ), 1151-1159.

Ng, K.K., Lin, C.F., Panchangam, S.C., Hong, A.P.K., Yang, P.Y., 2011. Reduced membrane fouling in a novel bio-entrapped membrane reactor for treatment of food and beverage processing wastewater. Water Research 45(14), 4269-4278.

Nguyen, T.T., Ngo, H.H., Guo, W., 2013. Pilot scale study on a new membrane bioreactor hybrid system in municipal wastewater treatment. Bioresource Technology 141,8-12.

Pastor, L., Mangin, D., Barat, R., Seco, A., 2008. A pilot-scale study of struvite precipitation in a stirred tank reactor: Conditions influencing the process. Bioresource Technology 99(14), 6285-6291.

Phattaranawik, J., Leiknes, T.O., 2011. Extractive biofilm membrane bioreactor with energy recovery from excess aeration and new membrane fouling control. Bioresource Technology 102(3), 2301-2307. 
Pollice, A., Laera, G., Saturno, D., Giordano, C., 2008. Effects of sludge retention time on the performance of a membrane bioreactor treating municipal sewage. Journal of Membrane Science 317(1-2), 65-70.

Qiu, Y., Shi, H.C., He, M., 2010. Nitrogen and phosphorous removal in municipal wastewater treatment plants in China: A review. International Journal of Chemical Engineering, $1-10$.

Stephenson, T., Judd, S., Jefferson, B., Brindle, K., 2000. Membrane Bioreactors for Wastewater Treatment, IWA Publishing, London.

Third, K.A., Burnett, N., Cord-Ruwisch, R., 2003. Simultaneous nitrification and denitrification using stored substrate (phb) as the electron donor in an SBR. Biotechnology and Bioengineering 83(6), 706-720.

Trussell, R.S., Merlo, R.P., Hermanowicz, S.W., Jenkins, D., 2006. The effect of organic loading on process performance and membrane fouling in a submerged membrane bioreactor treating municipal wastewater. Water Research 40(14), 2675-2683.

Wang, B., Wang, W., Han, H., Hu, H., Zhuang, H., 2012. Nitrogen removal and simultaneous nitrification and denitrification in a fluidized bed step-feed process. Journal of Environmental Sciences 24(2), 303-308.

Xia, S., Guo, J., Wang, R., 2008. Performance of a pilot-scale submerged membrane bioreactor (MBR) in treating bathing wastewater. Bioresource Technology 99(15), 6834-6843.

Xia, S., Li, J., He, S., Xie, K., Wang, X., Zhang, Y., Duan, L., Zhang, Z., 2010. The effect of organic loading on bacterial community composition of membrane biofilms in a submerged polyvinyl chloride membrane bioreactor. Bioresource Technology 101(17), 6601-6609.

Yang, S., Yang, F., Fu, Z., Lei, R., 2009. Comparison between a moving bed membrane bioreactor and a conventional membrane bioreactor on membrane fouling. Bioresource Technology 100(24), 6655-6657.

\section{Figure captions}

Fig. 1. The FBR-MBR combo process units.

Fig. 2. Removal efficiencies of $\mathrm{COD}, \mathrm{NH}_{4}{ }^{+}-\mathrm{N}$ and $\mathrm{PO}_{4}{ }^{3-}-\mathrm{P}$ from $\mathrm{FBR}, \mathrm{MBR}_{\mathrm{C}}$ and $\mathrm{FBR}-\mathrm{MBR} \mathrm{C}_{\mathrm{C}}$ 


$$
\begin{aligned}
& \text { under constant operating conditions }\left(\mathrm{pH}_{\mathrm{FBR}}=9 \text {, IAC (on/off }\right)=45 / 15 \mathrm{~min}, \mathrm{HRT}_{\mathrm{FBR}}=2 \mathrm{~h} \text {, } \\
& \mathrm{HRT}_{\mathrm{MBR}}=6 \mathrm{~h} \text { and extended SRT). }
\end{aligned}
$$

Fig. 3. Fig. 3. Concentration and removal efficiency of $\mathrm{NH}_{4}{ }^{+}-\mathrm{N}$ and total kjeldahl nitrogen (TKN) under constant operating conditions $\left(\mathrm{FBR}-\mathrm{MBR}_{\mathrm{C}}\right)$.

Fig. 4. Comparison of TMP (1 inHg=3.38 kPa) variation between $\mathrm{MBR}$ sytem without FBR and FBR-MBR ${ }_{C}$ combo system.

Fig. 5. Effects of various operating parameters on $\mathrm{PO}_{4}{ }^{3-}-\mathrm{P}, \mathrm{NH}_{4}{ }^{+}-\mathrm{N}$ and $\mathrm{COD}$ removal efficiency in FBR-MBR ${ }_{V}$ combo system (a) pH (b) HRT (c) SRT.

Fig. 6. Effect of different operating conditions on SMP, EPS, TMP ( $1 \mathrm{inHg}=3.38 \mathrm{kPa}) \quad$ and MLSS concentrations for FBR-MBR ${ }_{V}$ combo system (a) $\mathrm{pH}$ (b) Hydraulic retention time (HRT) (c) Sludge retention time (SRT) (d) Intermittent aeration cycle (IAC). 


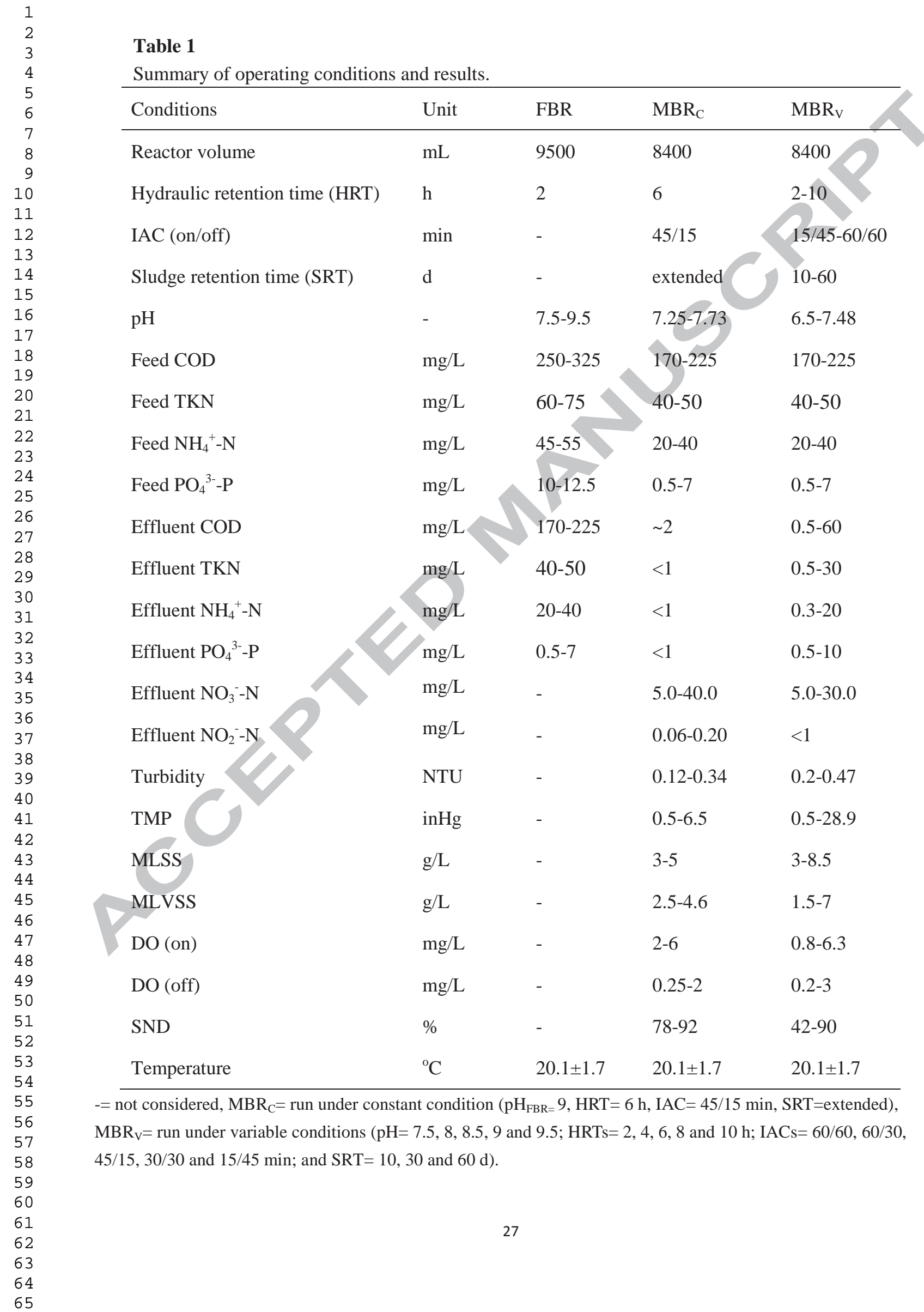


Table 2

1 The $\mathrm{pH}$ values at different sampling locations in the FBR-MBR combo system.

\begin{tabular}{|c|c|c|c|c|c|c|c|c|c|c|}
\hline \multirow{2}{*}{\multicolumn{2}{|c|}{$\begin{array}{l}3 \text { Sample }(\mathrm{n}=183) \\
4\end{array}$}} & \multirow{2}{*}{ Feed } & \multirow{2}{*}{ FBR } & \multirow{2}{*}{ Supernatant } & \multicolumn{2}{|c|}{$\mathrm{MBR}_{\mathrm{C}}$} & \multicolumn{2}{|c|}{$\mathrm{MBR}_{\mathrm{V}}$} & \multicolumn{2}{|c|}{ Effluent $^{\mathrm{b}}$} \\
\hline & & & & & on & off & on & off & $\mathrm{E}_{1}$ & $E_{2}$ \\
\hline $\begin{array}{l}6 \\
7 \mathrm{pH}\end{array}$ & Mean & 6.39 & 9.06 & 8.76 & 7.25 & 7.73 & 6.50 & 7.48 & & 7.30 \\
\hline 8 & Std & 0.80 & 0.47 & 0.57 & 0.59 & 0.50 & 0.68 & 0.72 & 0.61 & 0.69 \\
\hline$\theta$ & \multicolumn{4}{|l|}{$\mathrm{p}$-value $\mathrm{e}^{\mathrm{a}}$} & \multicolumn{2}{|c|}{ 6.63E-21 } & \multicolumn{2}{|c|}{$4.11 \mathrm{E}-13$} & & \\
\hline $\begin{array}{l}2 \\
3 \\
4 \\
5 \\
6\end{array}$ & $\begin{array}{l}\text { a = t-test (p } \\
\text { combined } \\
\text { Std= stand } \\
\text { "on" and “ }\end{array}$ & $\begin{array}{l}\text { luent c } \\
\text { deviat } \\
\text { ?. }\end{array}$ & cted du & $\begin{array}{l}\text { red significant } \\
\mathrm{n} / \text { off aeration } \\
\text { surement ( } \mathrm{n}=1\end{array}$ & $\begin{array}{l}\text { for M } \\
\text { onditic } \\
\text { 83) wa }\end{array}$ & $\begin{array}{l}\mathrm{s}\left(\mathrm{E}_{1}=\right. \\
\text { conside }\end{array}$ & $\begin{array}{l}\text { unde } \\
\text { efflue } \\
\text { cycle a }\end{array}$ & $\begin{array}{l}\text { /off c } \\
\text { nd } E_{2} \\
\text { funct }\end{array}$ & $\begin{array}{l}s^{b}= \\
\text { effluen } \\
\text { air pur }\end{array}$ & \\
\hline
\end{tabular}


Table 3

1 3 4

Comparison of removal efficiency of this study and other studies.

\begin{tabular}{|c|c|c|c|c|c|c|}
\hline \multirow[t]{2}{*}{ Wastewater type } & \multirow[t]{2}{*}{ Treatment approach } & \multirow{2}{*}{$\begin{array}{l}\text { HRT } \\
\text { (h) }\end{array}$} & \multicolumn{3}{|c|}{ Removal (\%) } & \multirow[t]{2}{*}{ References } \\
\hline & & & $\mathrm{NH} 4^{+}-\mathrm{N}$ & $\mathrm{PO}_{4}^{3-}-\mathrm{P}$ & COD & \\
\hline Synthetic & FBR-MBR & 6 & 98.7 & 93.0 & 99.3 & This study \\
\hline Synthetic & Sponge-MBR & 6 & $>99$ & $>98.8$ & $>96$ & Guo et al., 2009 \\
\hline Piggery & CP-MBR & 48 & 98.2 & - & 99.4 & Kornboonraksa et al., 2009 \\
\hline Food and beverage & Bio-entrapped-MBR & $6-12$ & - & - & $93-98$ & Ng et al., 2011 \\
\hline Municipal & GACS-FBBR-MBR & 7.5 & 95 & 70 & 90 & Nguyen et al., 2013 \\
\hline Semi-synthetic food & BF-MBR & 11 & 99.2 & - & 90.6 & Phattaranawik and Leiknes, 2011 \\
\hline Synthetic & MB-MBR & 18 & 90.8 & & 95.4 & Yang et al., 2009 \\
\hline Synthetic & MBR & 36 & 90.6 & 90.5 & $>95$ & Fu et al., 2009 \\
\hline Synthetic & MBR & 7 & 99 & 100 & 96 & Ding et al., 2011 \\
\hline Synthetic & MBR & 4 & $32-45$ & $>95$ & $32.7-95$ & Holakoo et al., 2007 \\
\hline Synthetic & MBR & 8 & 95.7 & - & 88.2 & Wang et al., 2012 \\
\hline Synthetic & MBR & 8 & 96.9 & - & $94-96$ & Xia et al., 2010 \\
\hline Bathing & MBR & 8 & 93 & - & 99 & Xia et al., 2008 \\
\hline Synthetic & FRR & - & - & $>90$ & - & Adnan et al., 2003 \\
\hline Anaerobic liquor & & - & 4 & 90 & - & Fattah et al. 2008 \\
\hline Synthetic & & - & $13-70$ & $60-98$ & - & Guadie et al. 2013 \\
\hline Synthetic & FBR & - & $20-59$ & $75-80$ & & Le Corre et al., 2007 \\
\hline Dewatering liquor & FBR & - & - & 94 & - & Munch and Barr, 2001 \\
\hline Synthetic & FBR & - & - & $40-80$ & - & Pastor et al., 2008 \\
\hline
\end{tabular}

$-=$ not mentioned, $\mathrm{FBR}=$ fluidized bed reactor, $\mathrm{MBR}=$ membrane reactor, $\mathrm{CP}=$ chemical precipitation, $\mathrm{GACS}-\mathrm{FBBR}=$ granular activated carbon-sponge fluidized bed bioreactor, $\mathrm{BF}=$ biofilm, $\mathrm{MB}=$ moving bed. 


\section{Table 4}

Effect of aeration cycles on FBR-MBR ${ }_{V}$ combo system performance.

\begin{tabular}{|c|c|c|c|c|c|c|}
\hline \multicolumn{2}{|c|}{ Aeration Cycle (min) } & \multicolumn{2}{|c|}{$\mathrm{DO}(\mathrm{mg} / \mathrm{L})$} & \multicolumn{3}{|c|}{ Removal efficiency (\%) } \\
\hline on & off & on & off & COD & $\mathrm{NH}_{4}^{+}-\mathrm{N}$ & $\mathrm{PO}_{4}^{3-}-\mathrm{P}$ \\
\hline 60 & 60 & $6.3 \pm 1.2$ & $3.0 \pm 0.2$ & $99.2 \pm 0.7$ & $99.1 \pm 0.6$ & $89.7 \pm$ \\
\hline 60 & 30 & $4.1 \pm 2.1$ & $1.5 \pm 0.5$ & $99.4 \pm 0.5$ & $98.6 \pm 0.4$ & $93.6 \pm 2.0$ \\
\hline 45 & 15 & $3.1 \pm 0.7$ & $1.4 \pm 0.6$ & $98.7 \pm 0.8$ & $99.3 \pm 0.3$ & $92.5 \pm 1.0$ \\
\hline 30 & 30 & $1.5 \pm 1.0$ & $0.3 \pm 0.0$ & $87.0 \pm 2.3$ & 2.5 & $95.4 \pm 0.6$ \\
\hline 15 & 45 & $0.8 \pm 0.2$ & $0.2 \pm 0.1$ & $78.4 \pm 4.2$ & $62.7 \pm 1.4$ & $94.2 \pm 1.7$ \\
\hline
\end{tabular}


1

2

3

4

5

6

7

8

10

11

12

13

14

15

16

17

18

19

20

21

22

23

24

25

26

27

28

29

30

31

32

33

34

35

36

37

38

39

40

41

42

43

44

45

46

47

48

49

50

51

52

53

54

55

56

57

58

59

60

61

62

63

64

65

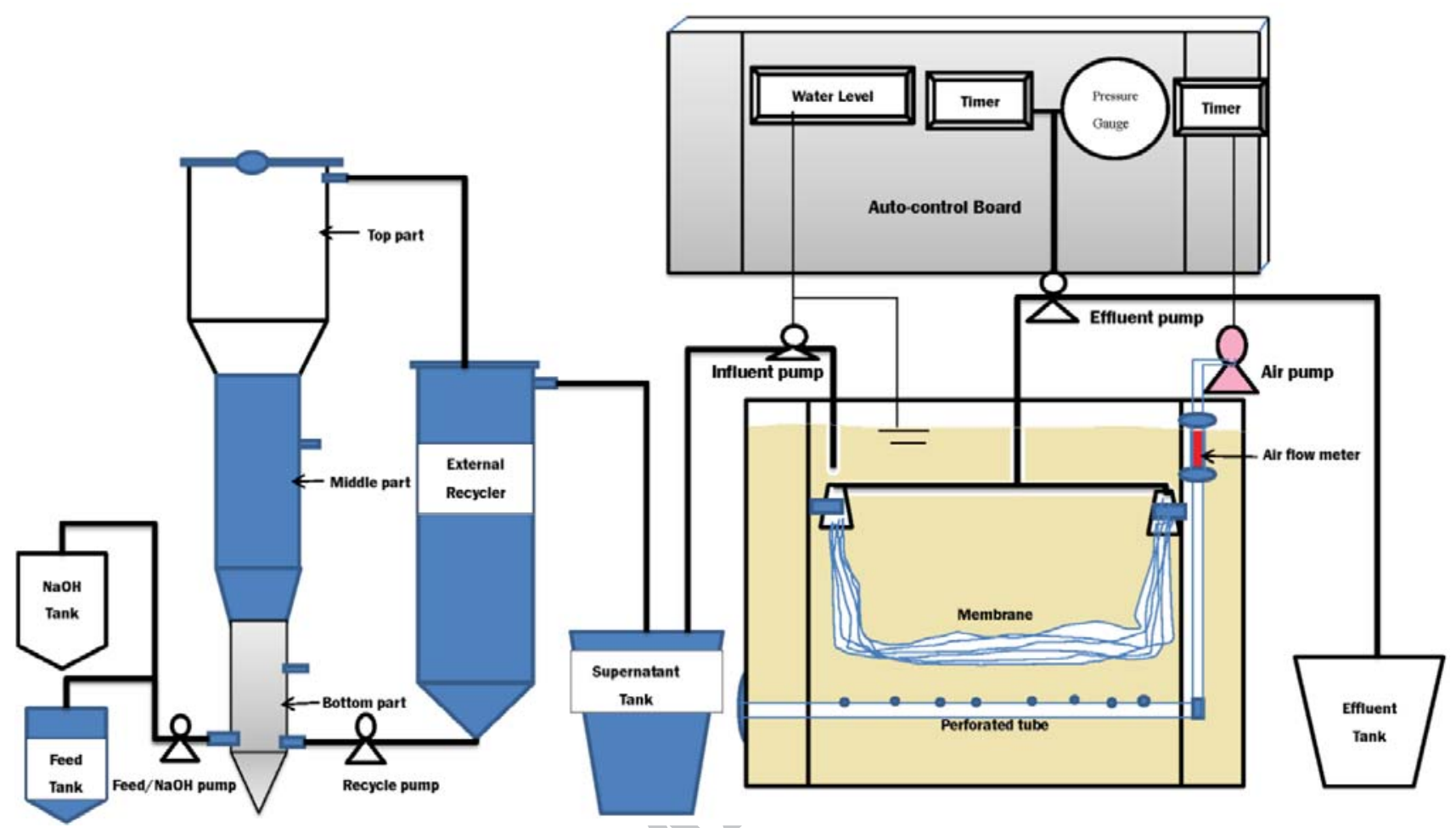

Fig. 1. The FBR-MBR combo process units. 


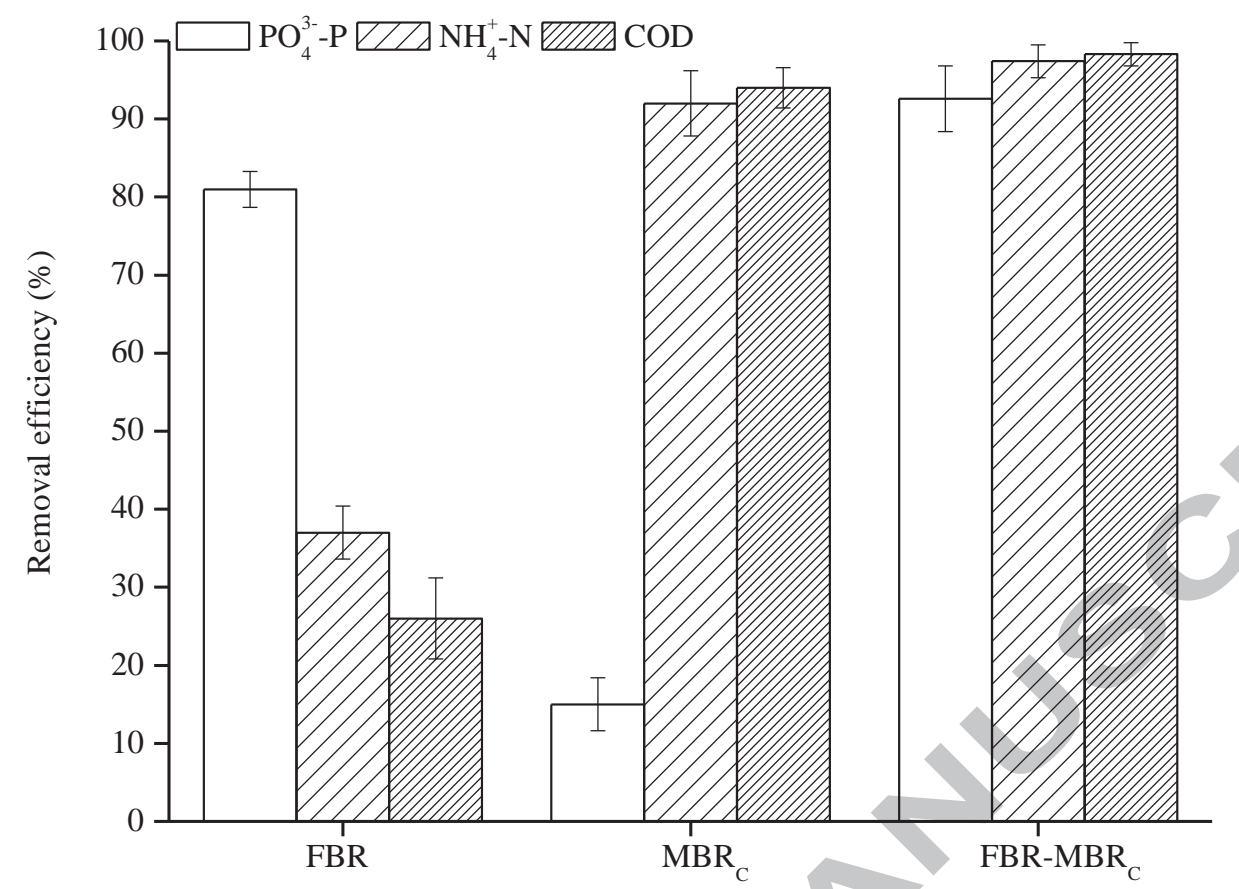

Fig. 2. Removal efficiencies of $\mathrm{COD}, \mathrm{NH}_{4}{ }^{+}-\mathrm{N}$ and $\mathrm{PO}_{4}{ }^{3-}-\mathrm{P}$ from $\mathrm{FBR}, \mathrm{MBR}_{\mathrm{C}}$ and $\mathrm{FBR}-\mathrm{MBR}_{\mathrm{C}}$ under constant operating conditions $\left(\mathrm{pH}_{\mathrm{FBR}}=9\right.$, IAC (on/off) $=45 / 15 \mathrm{~min}, \mathrm{HRT}_{\mathrm{FBR}}=2 \mathrm{~h}$, $\mathrm{HRT}_{\mathrm{MBR}}=6 \mathrm{~h}$ and extended SRT). 


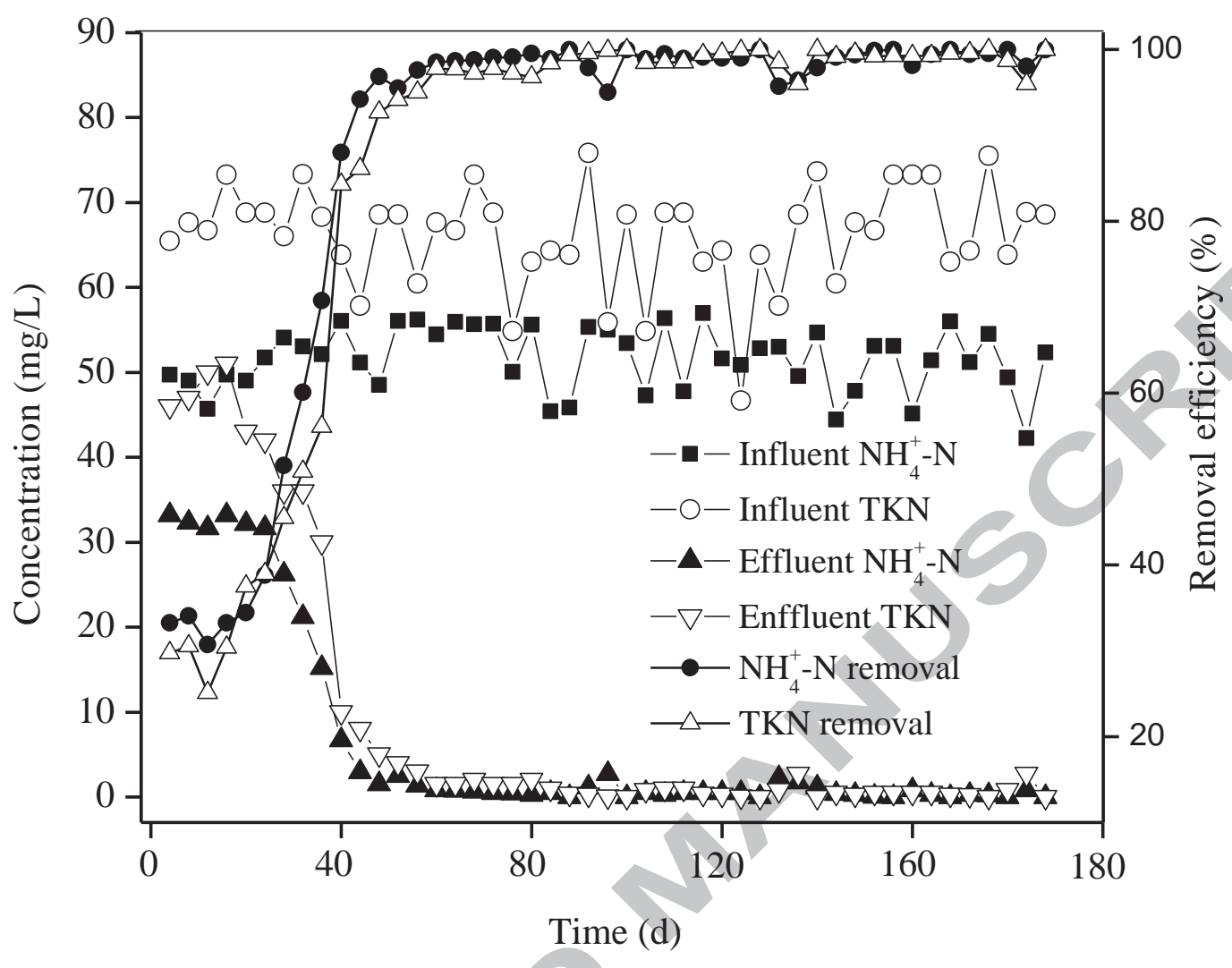

Fig. 3. Concentration and removal efficiency of $\mathrm{NH}_{4}{ }^{+}-\mathrm{N}$ and total kjeldahl nitrogen (TKN) under constant operating conditions (FBR-MBR $)$. 
1

2

3

4

5

6

7

8
9

10

11

12

13

14

15

16

17

18

19

20

21

22

23

24

25

26

27

28

29

30

31

32

33

34

35

36

37

38

39

40

41

42

43

44

45

46

47

48

49

50

51

52

53

54

55

56

57

58

59

60

61

62

63

64

65

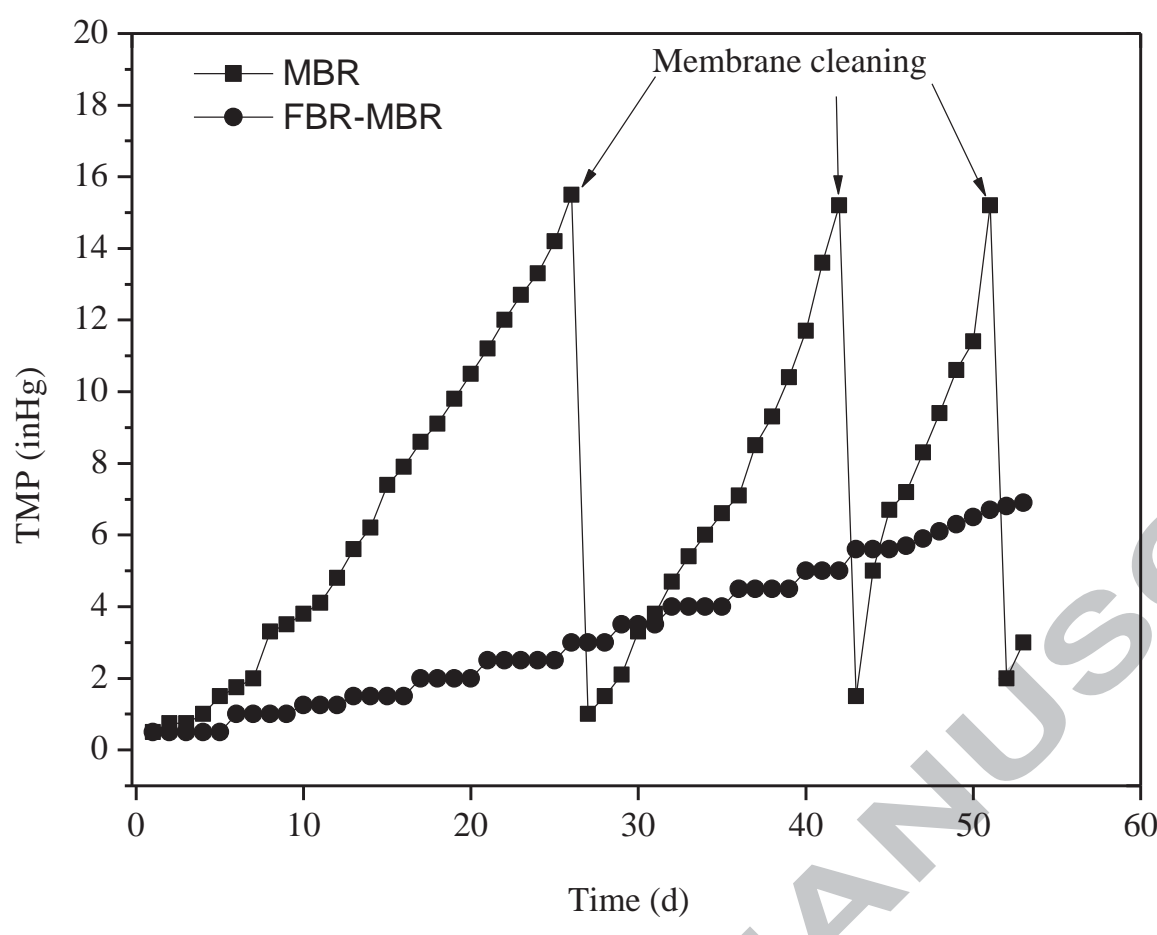

Fig. 4. Comparison of TMP ( $1 \mathrm{inHg}=3.38 \mathrm{kPa})$ variation between MBR sytem without FBR and FBR-MBR $\mathrm{C}_{\mathrm{C}}$ combo system. 

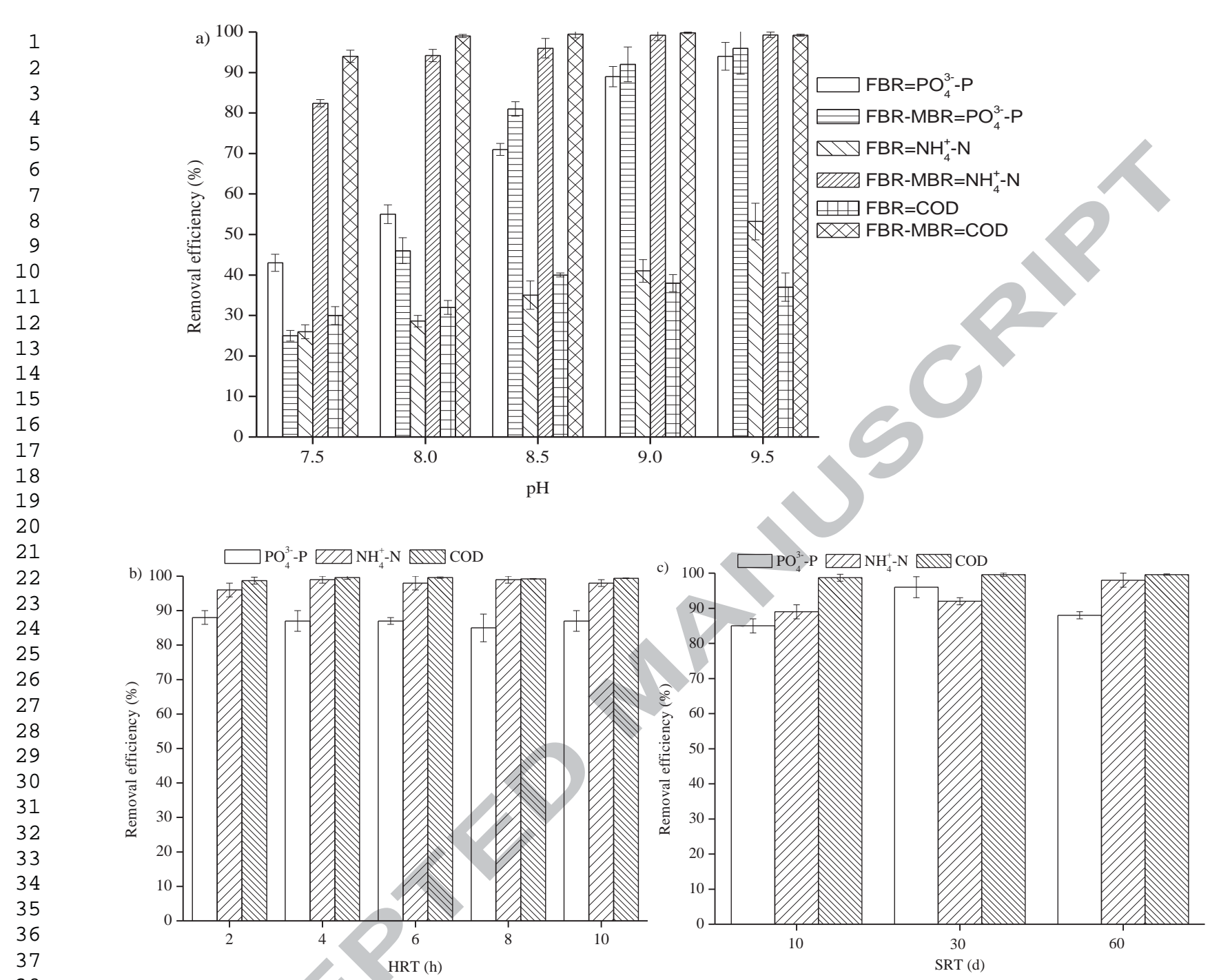

Fig. 5. Effects of various operating parameters on $\mathrm{PO}_{4}{ }^{3-}-\mathrm{P}, \mathrm{NH}_{4}{ }^{+}-\mathrm{N}$ and $\mathrm{COD}$ removal efficiency in FBR-MBR ${ }_{V}$ combo system (a) pH (b) HRT (c) SRT. 

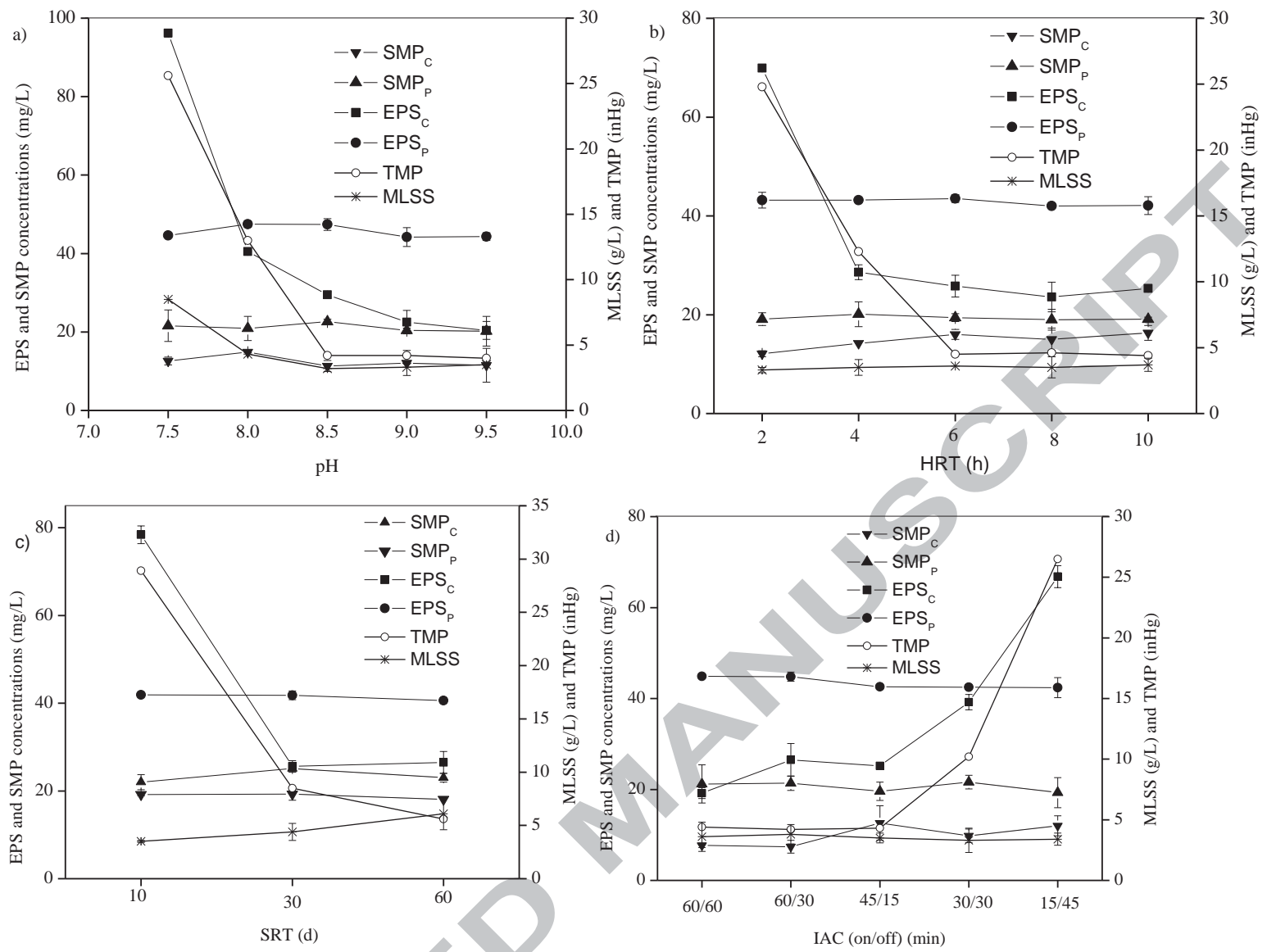

Fig. 6. Effect of different operating conditions on SMP, EPS, TMP (1 inHg=3.38 kPa) and MLSS concentrations for FBR-MBR ${ }_{V}$ combo system (a) $\mathrm{pH}$ (b) Hydraulic retention time (HRT) (c) Sludge retention time (SRT) (d) Intermittent aeration cycle (IAC). 


\section{Highlights}

- FBR-MBR combo system was promising in treating phosphorus and nitrogen in sewage.

- Combing the FBR with MBR was proved to work in harmony without any $\mathrm{pH}$ adjustment.

- Intermittent aeration enhanced simultaneous nitrification-denitrification activity.

- The combo system was successful in mitigating membrane fouling.

- Struvite recovery at low phosphorus concentration was confirmed. 